\title{
Henoch-Schonlein purpura with multiple symptoms in adult patient: a case report
}

\author{
Amin Dalili ${ }^{1}$, Behzad Gholamveisi ${ }^{2}$, Sara Rahimi ${ }^{3}$, Abed Ebrahimi ${ }^{4}$, Mostafa Sadeghi $^{5}$ \\ ${ }^{1}$ Surgical Oncology Research Center, Faculty of Medicine, Mashhad University of Medical Sciences, Mashhad, Iran \\ 2 Department of Operating Room, Faculty of Nursing and Midwifery, Kurdistan University of Medical Sciences, \\ Sanandaj, Iran \\ ${ }^{3}$ Student Research Committee, Kurdistan University of Medical Sciences, Sanandaj, Iran \\ ${ }^{4}$ Department of Operating Room, Faculty of para medicine, Bushehr University of Medical Sciences, Bushehr, iran \\ ${ }^{5}$ Montaserie Organ Transplantation and Dialysis Center, Mashhad University of Medical Sciences, Mashhad, Iran
}

\begin{abstract}
Background: Henoch-Schonlein purpura is a common systemic vasculitis in childhood, usually characterized by skin, abdominal, and renal manifestations. Most patients are 4 to 7 years old and are more common in boys. The disease is very rare in adults with multiple symptoms.

Case Report: A 20-year-old male patient with final diagnosis of Henoch-Schonlein disease with rare complications was admitted in our center. The patient referred to the hospital with acute abdomen and free fluid in the abdominal space and underwent appendectomy. During the hospitalization of the patient, purpura in the lower limb and acute scrotum were developed, which treatment was successfully performed. Disease and treatment approach of this patient has significant points that are listed below.

Conclusion: incidence of multiple symptoms in Henoch-Schonlein purpura is very rare in adults and may cause organ failure. Therefore, its symptoms should always be considered and appropriate diagnostic measures should be taken to prevent unnecessary surgery. Careful attention and frequent examinations by the surgeon in patients with abdominal complications are also essential.
\end{abstract}

Keywords: Henoch-Schonlein, Purpura, Multiple, Symptoms, Adult, Patient.

Cited as: Dalili A, Gholamveisi B, Rahimi S, Ebrahimi A, Sadeghi M. Henoch schonlein purpura with multiple symptoms in adult patient: a case report. Medical Science Journal of Islamic Azad University, Tehran Medical Branch 2020; 30(4): 453-458.

Correspondence to: Mostafa Sadeghi

Tel: +9809187804983

E-mail: Behzad.gholamveisi@gmail.com

ORCID ID: 0000-0001-6816-5571

Received: 21 Jun 2020; Accepted: 18 Apr 2020 
مجله علوم يزشكى دانشگاه آزاد اسلامى

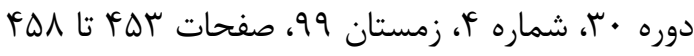

Case

Report

\title{
يوريوراى هنوخ شوئن لاين با علايم متعدد در بيمار بالغ: گزارش مورد
}

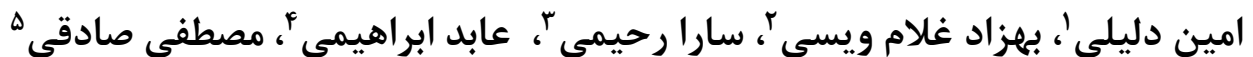

$$
\begin{aligned}
& \text { ' مركز تحقيقات جراحى اونكولوزى، دانشكده يزشكى، دانشكاه علوم يزشكى مشهر، مشهر، ايران }
\end{aligned}
$$

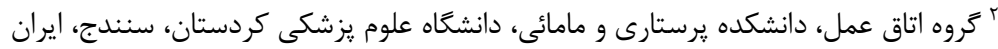

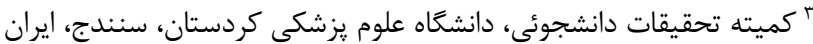

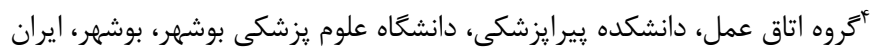

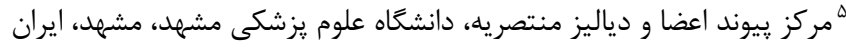

سابقه و هدف: بوريوراى هنوخ شوئن لاين يك واسكوليت سيستميكى شايع در سنين كودكى /ست كه معمولا با تظاهرات بوستى،

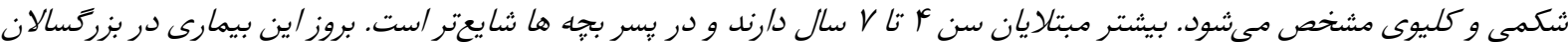

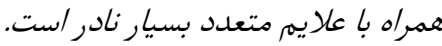

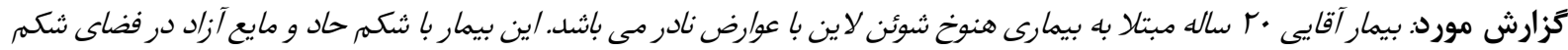

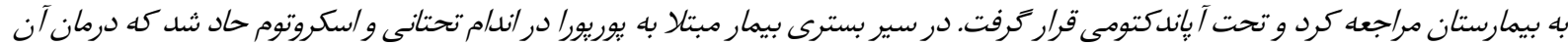

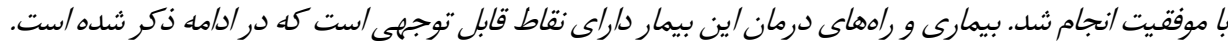

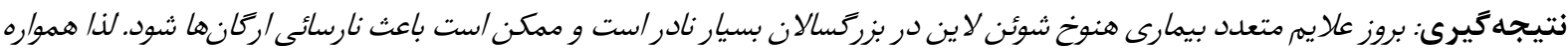

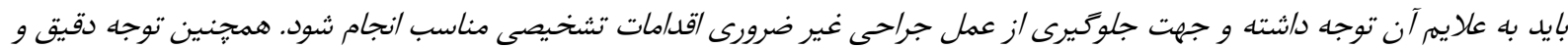

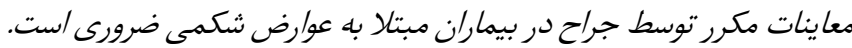
وازًان كليدى: يوريورا، هنوخ شوئن لاين، علايم، متعدد، بيمار، بالغ.

شروع بيمارى مطرح هستند و بيمارى با رسوب ايمنوكلوبولين مقدمه

A در عروق ريز بدن اتفاق مىافتد (با, عا).

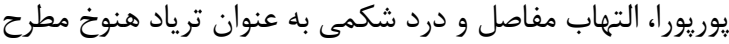

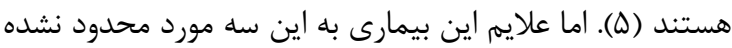

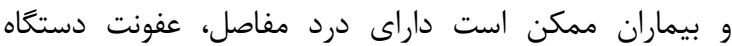

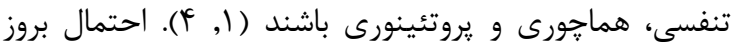
مشكلات سيستم عصبى مركزى، دركيرى بافت ريه، التهاب

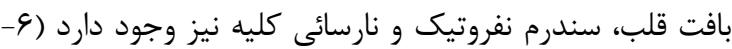
(ا). در برخى بيماران خونريزى، تورم و درد بيضه، إيبديديميت،

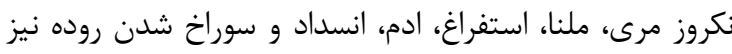

$$
\text { كزارش شده است (له, \, ^). }
$$

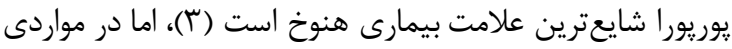
بيمارى بدون وجود يوريورا نيز كزارش شده است (9). يوريوراها يوريوراى هنوخ شوئنلاين يكى از واسكوليتهاى نكروزان عروق كوجى در دوره كودكى است و بسته به سن، شيوع آن آن از 9 تان

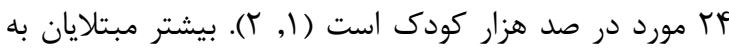

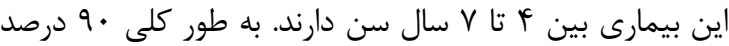

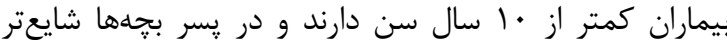

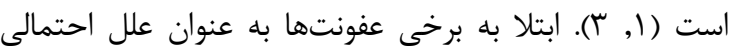

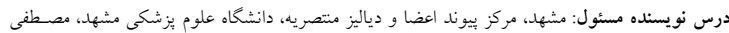
صادقى (email: Behzad.gholamveisi@gmail.com) ORCID ID: 0000-0001-6816-5571 تاريخ دريافت مقاله:

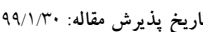


در سونوگرافى شكم و لخن، كبد، طحال، كليه و پانكراس با اندازه و اكوى گارانشيمال نرمال مشاهده شدند. كيسه صفرا متسع بود و داراى نواحى هاييردانس داخلى (اسلاز) و حاوى سنخريزه مشاهده شد. يلورال افيوزن در ناحيه همى توراكس جٍِ وجود داشت.

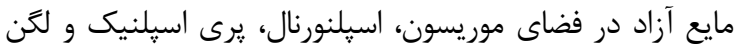
مشاهده شد.

بيمار با تشخيص شكم حاد كانديد عمل شد و يس از انجام مراقبتهاى لازم به اتاق عمل منتقل شد. تحت بيهوشى عمومى

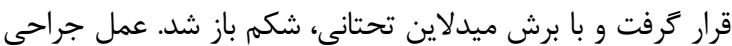
آياندكتومى به انجام رسيد و آيانديس ملتهب خارج شد. يس از اتمام عمل، بيمار به بخش جراحى منتقل شد و تحت مراقبت قرار

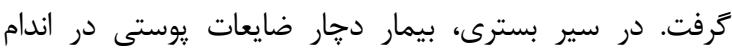
تحتانى دو طرف شد، و ادم و درد اسكروتوم طرفين نيز در بيمار

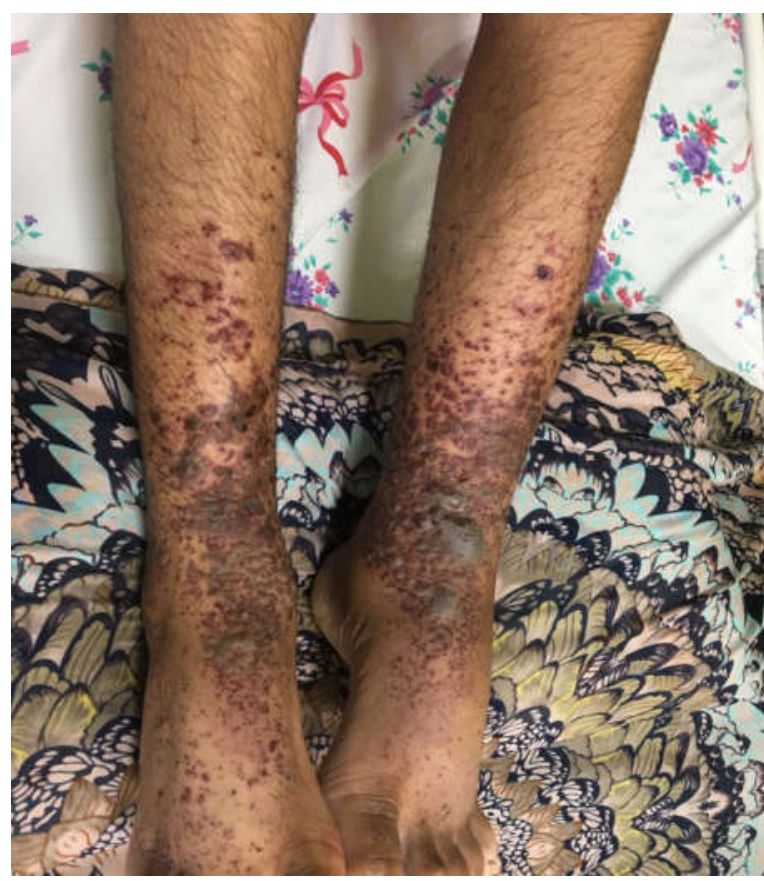

شكل ا. وجود ضايعات يوستى بر روى اندام تحتانى دو طرف

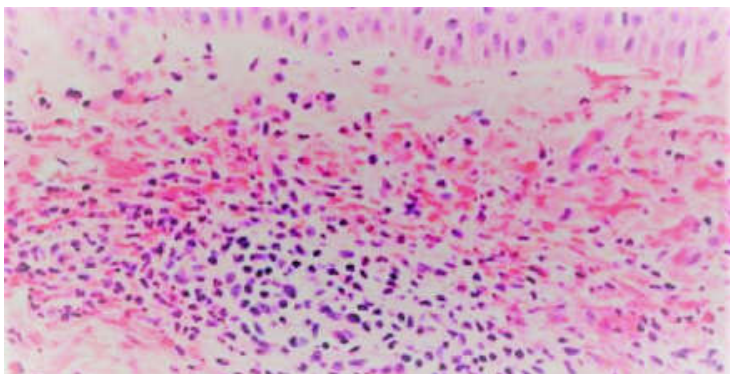

شكل r. پاتولوزى واسكوليت در بيمار
عمدتا بر روى باسن، سطوح اكستانسور ز ياها و ساعد مشاهده

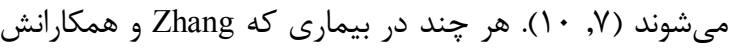
كزارش كردهاند، يوريورا فقط در كف يا وجود داشته است ( • (1). يوريوراهاى يوستى بدون مشكل هستند و اثر آنها بعد از جند : هند

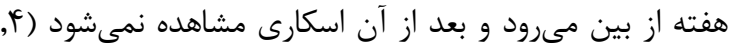

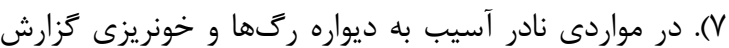
شده است كه منجر به نكروز يوستى و بروز اسكارهاى متعدد بر روى يوست بيمار شده است (V). تشخيصهاى افتراقى اين ضايعات يوستى شامل ترومبوسيتوينى، هموفيلى و انعقاد داخل عروقى منتشر هستند (V) (I) (1). در بين عوارض مختلف بيمارى، مشكلات كليوى خطرناكتر است و با افزايش سن احتمال بروز آنها نيز بيشتر مى مئنود (ب). جهت جلوگيرى از عوارض جبران نايذير، پيگيرى و درمان بايد به موقع شروع شود (1). درمان بيمارى بسته به عوارض اتفاق

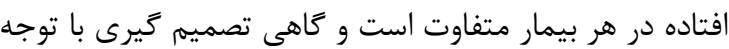

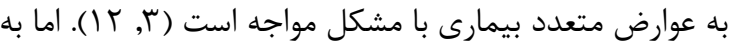
طور كلى جهت درمان مىتوان از داروهاى دخزامتازون، كلشى

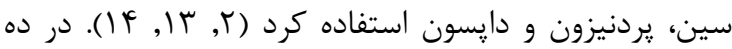
درصد بيماران با علايم شكمى احتياج به لاياراتومى وجود دارد (IT). در بيماران با تورم اسكروتوم و هماجورى نياز به انجام

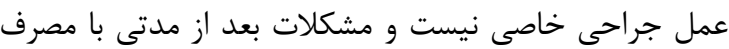
داروها رفع مىشود (r, ها ه).

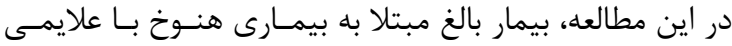

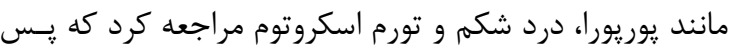

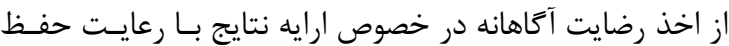

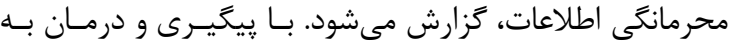

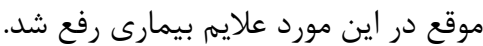

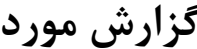

بيمار آقاى •r سالداى در مرداد ماه ^وسا به بيمارستان امام رضا (ع) شهر مشهد مراجعه كرد. بيمار از درد شكم با شروع از

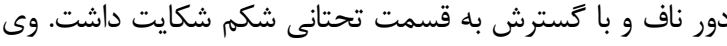
تب، سردرد، تهوع، استفراغ و بى اشتهايى داشت و سابقه بيمارى و جراحى خاصى را ذكر نمىكرد. شكم مريض نرم و بدون

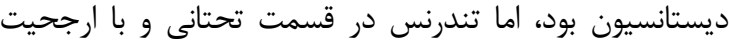
سمت راست وجود داشت. در آزمايش خون كامل، هموكلوبين

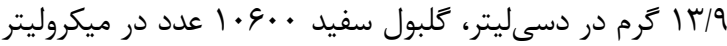

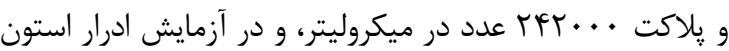

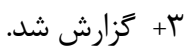



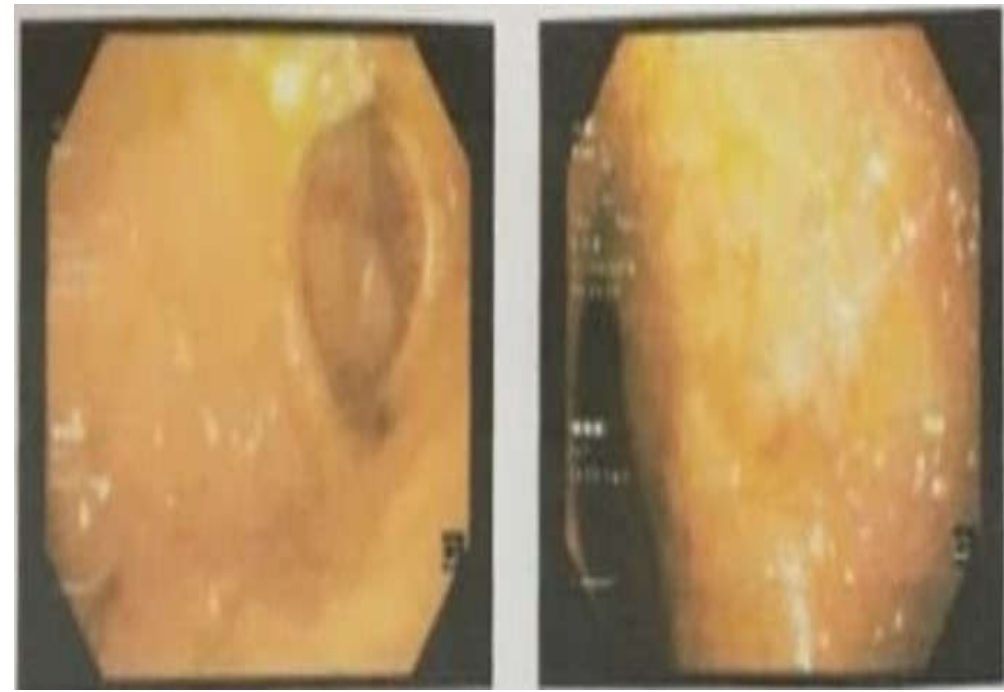

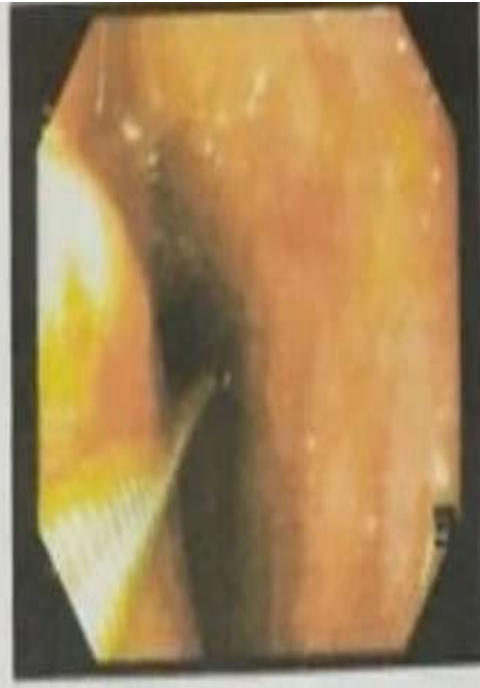

شكل r. وجود ضايعات اريتماتو و اروزيو در انترودئودنوم
كمتر از f|

بيمارى هنوخ شوئن لاين تحت عنوان يوريوراى آنافيلاكتوئيد

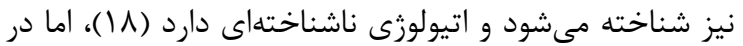
مواردى زنتيك و عفونتهاى ويروسى به عنوان عوامل

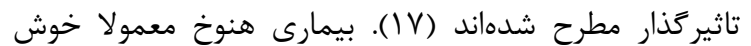

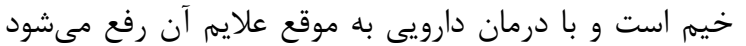

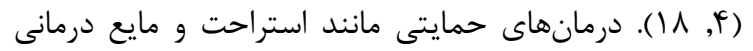

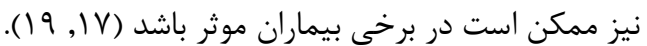
بيمارى هنوخ شوئن لاين عروق كوجى را را دركير مى مند و ممكن است باعث بروز مشكلات فشار خون شود (9 (1). با هيا دركير كردن عروق كوجى ممكن است علايم آن در تمام بدن بـن بروز كند، اما بيشتر با مشكلات يوستى و مفاصل همراه است

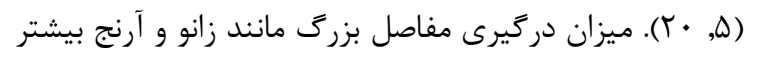

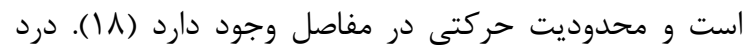
شكم نيز جزو علايم شايع است و در له درصد از بيماران

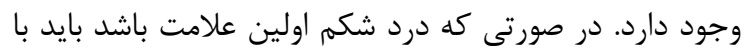

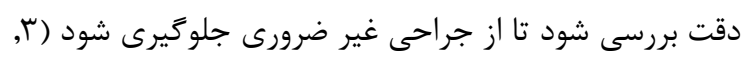
IV

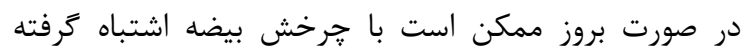

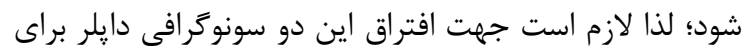
بيمار درخواست شود تا بيمار به اشتباه تحت عمل جراحى بر

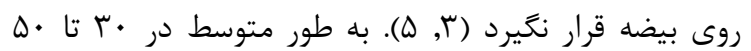

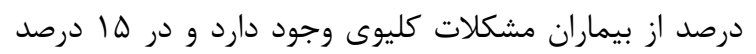

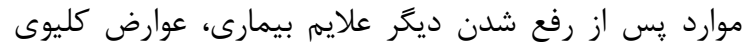

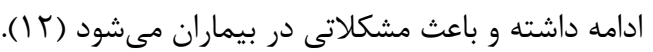

با مشاهده ضايعات يوستى در سطح اكستنسور اندام هاى تحتانى شك به واسكوليت و هنوخ شوئن لاين مطرح شد (شكل (1).

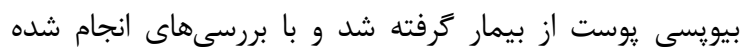
تشخيص واسكوليت هنوخ شوئن لاين داده شد (شكل ؟ ؟). با مشخص شدن بيمارى هنوخ شوئن لاين بررسىهاى تكميلى جهت بررسى عوارض ديگر اين بيمارى انجام شد. در بررسىهاى گَارشى، كولونوسكوبى نرمال و در اندوسكويى ضايعات اريتماتو و اروزيو در انترودئودنوم ديده شد (شكل ساب). سيس براى بيمار مشاوره نفرولوزى درخواست شد كه با بررسى درونى هاى انجام شده مسائل سندروم نفروتيك رد شد. در بيمار التهاب و قرمزى اسكروتوم مشهود بود و از درد در اين ناحيه شكايت

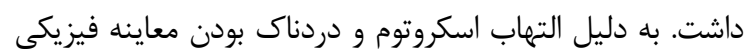
با مشكل روبرو بود. براى بيمار سونوگرافى دايلر درخواست شد و

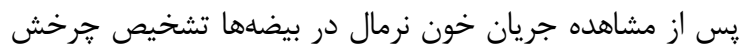

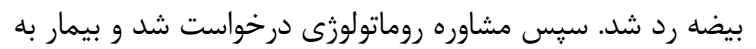
سرويس روماتولوزى انتقال يافت. التهاب مفاصل با داروهاى ضد التهاب رفع شد و بيمار يس از عا روز از بيمارستان ترخيص شدول

\section{بحث}

بيمارى هنوخ شوئن لاين اولين بار توسط ويليام هبردن توصيف شد (ه ()). اين بيمارى معمولا با درد و التهاب همراه است و بيشترين ميزان بروز آن در كودكان است. به طور متوسط اين بيمارى در أl نفر از هر صدهزار كودى مشاهده

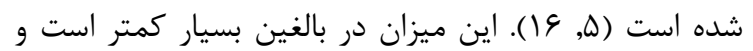




$$
\begin{aligned}
& \text { بنابراين توصيه مىشود در بيمارانى كه با درد شكم، تورم }
\end{aligned}
$$

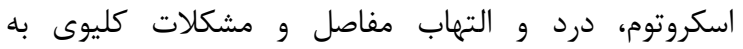

$$
\begin{aligned}
& \text { بيمارستان مراجعه مى كنند، همواره ابتلا به بيمارى هنوخ }
\end{aligned}
$$

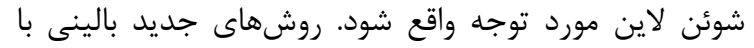

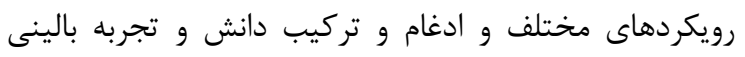

$$
\begin{aligned}
& \text { براى تعميم نتايج مطالعات بالينى مبتنى بر شواهد در خصني }
\end{aligned}
$$

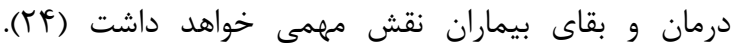

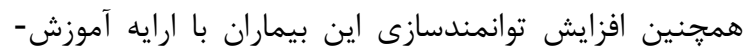

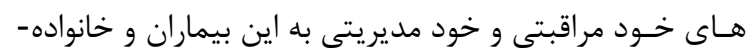

$$
\begin{aligned}
& \text { هاى آنان مىتواند بسيار كمك كننده باشد (Yه). }
\end{aligned}
$$

\section{تقدير و تشكر}

از بيمار و خانواده وى كه در راه كردآورى اطلاعات نهايت

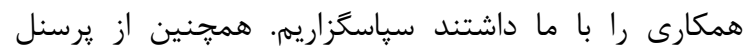

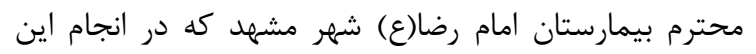

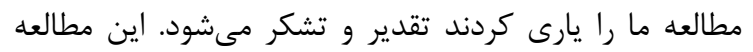

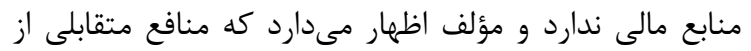

$$
\text { تاليف و يا انتشار اين مقاله ندارد. }
$$

احتمال عود مجدد بيمارى هنوخ يس از طى شدن دوره درمان وجود دارد كه موارد بعدى عود با علايم خفيفتر اتفاق مى دافتد

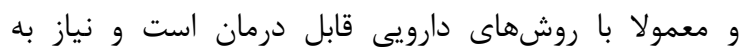
مداخله خاصى وجود ندارد (ז, ؟).

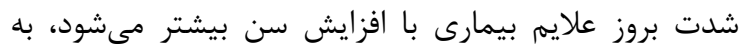

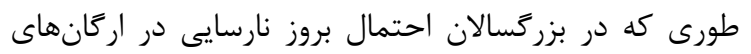

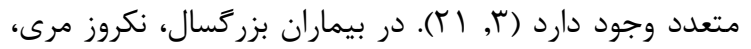

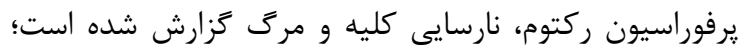
لذا در بيماران هنوخ بايد به علايم مختلف بسيار دقت كرد تاليه

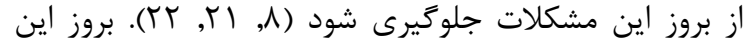

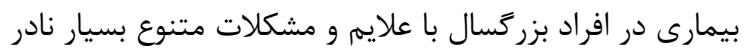

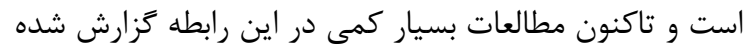

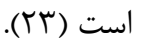
يوريوراى هنوخ شوئن لاين بيمارى مختص دوره كودكى است،

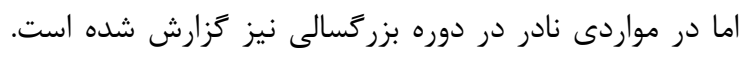

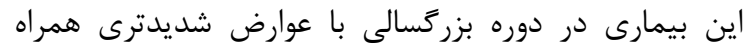

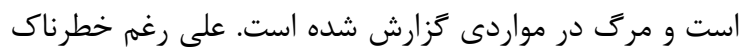

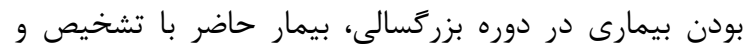

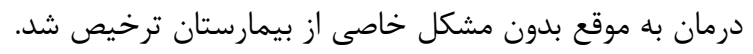

\section{REFERENCES}

1. Pohl M. Henoch-Schonlein purpura nephritis. Pediatr Nephrol 2015; 30:245-52.

2. Lee KH, Hong SH, Jun J, Jo Y, Jo W, Choi D, et al. Treatment of refractory IgA vasculitis with dapsone: a systematic review. Clin Exp Pediatr 2020; 63:158-163.

3. Moradinejad MH, Ziaee V, Marashi SM, Nasri Nasrabadi Z. Survey of clinical manifestations in Henoch Scha nlein purpura in follow up. Medical journal of Mashhad University of medical sciences (MJMS) 2014; 57:829-34. [In Persian]

4. Kiliç BD, Demir BK. Determination of Risk Factors in Children Diagnosed With Henoch-Schönlein Purpura. Arch Rheumatol 2018; 33:395.

5. Modi S, Mohan M, Jennings A. Acute scrotal swelling in Henoch-Schonlein purpura: Case report and review of the literature. Urol Case Rep 2016; 6:9-11.

6. Lei W-T, Tsai P-L, Chu S-H, Kao Y-H, Lin C-Y, Fang L-C, et al. Incidence and risk factors for recurrent HenochSchönlein purpura in children from a 16-year nationwide database. Pediatr Rheumatol 2018; 16:25.

7. Nothhaft M, Klepper J, Kneitz H, Meyer T, Hamm H, Morbach H. Hemorrhagic bullous Henoch-Schönlein Purpura: case report and review of the literature. Front Pediatr 2018; 6:413.

8. Iorio N, Bernstein GR, Malik Z, Schey R. Acute esophageal necrosis presenting with Henoch-Schönlein purpura. ACG Case Rep J 2015; 3:17.

9. Jarasvaraparn C, Lertudomphonwanit C, Pirojsakul K, Worawichawong S, Angkathunyakul N, Treepongkaruna S. Henoch-Schönlein without purpura: a case report and review literature. J Med Assoc Thai 2016; 99:441-5.

10. Zhang F, Chen L, Shang S, Jiang K. Atypical purpura location in a pediatric patient with Henoch-Schönlein purpura: A case report. Medicine 2018; 97:48.

11. Mahmood L, Zulfiqar F, Khalid S, Dillon M. P200 Management of henoch schonlein purpura (HSP) Archives of Disease in Childhood 2019;104:A238.

12. Jalali S. Spontaneous perforation of intestine in case of Henoch Schonlein syndrome. Razi Journal of Medical Sciences (RJMS) 1994; 1:15-9. [In Persian] 
13. Dixit N, Raj C, Behera D, Panda M. Drug-induced Henoch-Schonlein purpura with severe gastrointestinal involvement. Int J Dermatol 2019; 5:46.

14. Allali S, Fraitag S, Terrier B, Bodemer C, Chalumeau M. Efficacy of colchicine in a child with relapsing bullous Henoch-Schönlein purpura. Eur J Pediatr 2016; 175:147-9.

15. Adhikari P. Henoch-Schonlein Purpura Successfully Treated with Dexamethasone: A Case Report of Six-Year-Old Female. Journal of Medical Research and Innovation (JMRI) 2018; 2: 000095.

16. Reverte M, Etienne M, Fouchard M, Doucet L, Brenaut E, Misery L. Occurrence of Henoch-Schönlein purpura in a patient treated with secukinumab. J Eur Acad Dermatol Venereol 2019; 33:455-457

17. Kopparapu A, Jarrett D, Kraleti S, editors. IgA vasculitis presenting as abdominal pain and rash. Bayl Univ Med Cent 2019; 32:599-600.

18. Cui X-H, Liu H, Fu L, Zhang C, Wang X-D. Henoch-Schönlein purpura with intussusception and hematochezia in an adult: A case report. Medicine 2019; 98: 16981.

19. Yagi S, Endo I, Murakami T, Hida T, Yamamoto Y, Soga T, et al. Adult onset of Immunoglobulin A vasculitis-A case report. J Med Investig. 2019; 66:344-6.

20. Wilkinson A. Early recognition and treatment of Henoch-Schönlein purpura in children. Nurs Child Young People. $2019 ; 31: 36-40$

21. Maxfield L, Peck A, Youngblood LB. Adult Henolch-Schonlein purpura: multiorgan failure in the setting of a purpuric rash. BMJ Case Reports 2018; 2018.

22. Santos Cardoso F, Dias N, Barrote D, Oliveira Mendes MS, Ventura Góis MR, Viana HS, et al. A fatal case of severe gastrointestinal and renal involvement in Henoch-Schönlein purpura. J Nephropathol 2019; 8:31.

23. Cui J, Huang L-Y, Guo J, Wu C-R, Zhang B. Diagnosis and treatment of adult mixed-type Henoch-Schönlein purpura. Centr Eur J Immunol 2019; 44:138-143.

24. Kazemi Haki B, Moaddab S R, Rafii M R, Eftekhari M, Lebadi S, et al. The Effect of Sodium Selenite on the Acute Phase Protein Response and Plasma Variables in Patients Admitted in ICU, Jentashapir J Cell Mol Biol 2017; 9:65647.

25. Vafaei M, Azad M, Shiargar P, Kazemi Haki B. Quality of life in patients with thalassemia major referred to Ardabil Buali Hospital in 2012-13. Med sci 2015; 25:305-310. [In Persian] 